\title{
RESPONSABILIDADE SOCIAL ANALISADA À LUZ DA HERMENÊU- TICA CONSTITUCIONAL E DO ESTADO DEMOCRÁTICO DE DIREITO
}

\author{
SOCIAL RESPONSIBILITY CONSIDERED IN THE LIGHT \\ OF CONSTITUTIONAL HERMENEUTIC AND DEMOCRATIC RULE \\ OF LAW
}

Sharon Cristine Ferreira de Souza ${ }^{1}$

\begin{abstract}
RESUMO: Breve histórico a respeito da evolução dos modelos de Estado, juntamente com o desenvolvimento e a transição da Velha Hermenêutica à Nova Hermenêutica, baseada esta nos princípios que dão substrato à concepção de Estado Democrático de Direito e no princípio da dignidade da pessoa humana, mais especificamente sua relação com a função e responsabilidade social das empresas de acordo com o disposto nos artigos da Ordem Econômica e Financeira da Constituição Federal de 1988.
\end{abstract}

Palavras-Chave: Hermenêutica; Estado Democrático de Direito; Responsabilidade Social.

\begin{abstract}
Brief history about the evolution of the model state, along with developing and transition from Old to New Hermeneutics, based on the principles that give this substrate to the concept of Democratic Rule of Law State and the principle of human dignity, more specifically its relation to function and corporate social responsibility in accordance with the Articles of Economic and Financial Order of the Federal Constitution of 1988.
\end{abstract}

Keywords: Hermeneutics; Democratic State of Law; Social Responsibility.

\section{INTRODUÇÃO}

Tem-se como proposta uma análise breve da evolução histórica do modelo de Estado e sua relação com os métodos de interpretação, consistente na denominada Hermenêutica jurídica.

A relevância deste estudo é mostrar que, assim como se verificam mudanças e desenvolvimento nas relações políticas, econômicas, sociais e culturais no mundo do ser, devem-se criar técnicas interpretativas do texto do direito positivo e seus princípios que se adaptem aos anseios da sociedade, a fim de que se realizem os reclamos sociais.

\footnotetext{
${ }^{1}$ Mestre em Direito Negocial pela Universidade Estadual de Londrina e Doutoranda em Sociologia e Direito pela Universidade Federal Fluminense/RJ.
} 
Destaque aos princípios que balizam o Estado Democrático de Direito, principalmente, o da dignidade da pessoa humana, fundamento mais importante do Estado e diretriz a ser seguida na nova maneira de interpretação do Direito.

Observa-se que a idéia de responsabilidade social das empresas é uma realidade que necessita de maior discussão e regulamentação, principalmente no que concerne à diferenciação clara entre os conceitos de função e responsabilidade social, bem como a influência de seu comportamento em face dos interesses públicos. Deve-se levar em conta a relevância desse novo mecanismo do Direito que auxilia o Estado à trilhar o caminho do desenvolvimento e a garantir às empresas um vínculo de confiança com a sociedade.

Hermenêutica e interpretação

A Hermenêutica consiste em métodos de interpretação, maneiras de se buscar sentido e compreensão do mundo e das relações humanas. Embora não seja pacificado na doutrina, não se defende a idéia de "hermenêutica" e "interpretação" possuírem o mesmo conteúdo semântico, ou seja, não são consideradas palavras sinônimas. A primeira é uma área do conhecimento humano que disciplina princípios, métodos e orientações gerais com o intuito de viabilizar ao intérprete uma gama de técnicas a serem utilizadas para a interpretação, que nada mais é do que a aplicação prática dos ensinamentos da hermenêutica (NADER apud GOMES, 2002, p. 28).

Pode-se inferir que a hermenêutica jurídica são essas técnicas interpretativas aplicadas à deontologia, pois visam à interpretação dos textos normativos contidos no ordenamento jurídico.

Primordialmente a hermenêutica jurídica tinha a finalidade de buscar o sentido e preencher as lacunas - integração do ordenamento jurídico - do Direito Positivo. Por isso, a busca de instrumentalidade para a interpretação do Direito levou ao surgimento de algumas Escolas Hermenêuticas, que pensaram em técnicas para o melhor modo de aplicação no mundo do ser e do dever-ser. Apenas a título de exemplo, cabe citar algumas delas, como a Escola da Exegese, Escola Histórica, Escola da Livre Pesquisa Científica e Escola do Direito Livre (GOMES, 2002, p. 33-40).

Evolução histórica do modelo de estado e sua relação com a hermenêutica

Os métodos de interpretação não foram desenvolvidos sem nenhuma relação com os contecimentos históricos que o mundo verificou nesse mesmo espaço de tempo ${ }^{2}$. A interpreta2 "A juridicidade dos princípios passa por três distintas fases: a jusnaturalista, a positivista e a pós-positivista"
(BONAVIDES, 2003, p. 259). A primeira, cuja vigência durou até o advento da Escola Histórica do Direito,
tinha os princípios orbitando na esfera da extrema abstração, embasados principalmente nos ideais ético-valorati-
vos que inspiravam postulados de justiça. O positivismo, avesso às ingerências extrajurídicas no sistema norma-
tivo, postula os princípios como derivados das próprias leis e, aqueles erigidos ao patamar constitucional, vagos
mandamentos programáticos supralegais, carentes de imediata aplicação jurídica. Finalmente, pós-positivismo, 
ção servia para apreensão de normas jurídicas e de princípios tidos de forma isolada, mas precipuamente sua maior utilidade era na forma de mecanismo de integração do sistema jurídico, mediante o preenchimento de lacunas.

A denominada Velha Hermenêutica constitucional trazia os princípios como carentes de normatividade e, portanto, tinham função bastante subsidiária de preenchimento de vazios normativos, cujo intuito era garantir o reinado absoluto da lei (BONAVIDES, 2003, p. 262).

Isto porque esse modo interpretativo - modelo de integração - resultava da ideologia do Estado Abstencionista, influenciado pelo individualismo filosófico e liberalismo econômico, nos quais o poder estatal deveria respeitar a liberdade individual e não exercer qualquer ingerência no âmbito econômico e social, campo adstrito unicamente à atividade privada (PARODI, 1935 apud FILHO, 1998, p. 5-6).

Nesse período de política liberal, a sociedade seguia conforme o pensamento do laissez faire, laissez passer, le monde va de lui même $e^{3}$, expressão francesa que denotava a exigência de um retraimento do Estado no âmbito social, surgida na segunda metade do século XVIII com o advento das revoluções burguesas, principalmente na Inglaterra, França e Estados Unidos da América do Norte (VIEIRA, 2004, p. 196).

Com a abstenção do Estado em relação à sociedade ${ }^{4}$, a Hermenêutica estava destinada a criar maneiras de interpretação nas quais o princípio do Estado de Direito era o ideal máximo - constitucionalismo jurídico, tendo também como principais pilares a propriedade e o individualismo -, ou seja, cumpria-se unicamente aquilo que a lei posta autorizava e regulava e, na sua falta, e somente nesta, utilizava-se interpretação de princípio ou norma para suprimir o vácuo jurídico.

De fato, a abstenção do Estado proporcionou a emulação e desenvolvimento nas áreas técnica e científica, com o crescimento da produção e distribuição de bens. Contudo a dinâmica do capitalismo deixado ao sabor do mercado teve como corolário crises nefastas, causando

capitaneado por Ronald Dworkin, surge durante a crise positivista - a crise da Velha Hermenêutica -, trazendo normatividade aos princípios constitucionais, ou seja, atribuindo-lhes eficácia não apenas interpretativa, mas normativa, cuja aplicação é direta e imediata (p. 259-275).

3 "Deixar fazer, deixar passar, o mundo caminha por si mesmo".

${ }^{4}$ Contrariando a forma de Estado moderno absolutista, o pensamento de John Locke, um dos principais defensores do liberalismo, enfatiza a importância e o papel do legislativo, em que há poderes limitando o governo absoluto, mediante a criação de leis, não o depositando integralmente nas mãos do monarca. Os indivíduos seriam, desde o nascimento, iguais e livres, não devendo submissão a qualquer outro homem. Portanto, somente a decisão proveniente do povo deveria reger as leis estabelecidas para a comunidade civil. Conforme se verifica o crescimento da burguesia, juntamente com ela surge a insatisfação com as limitações impostas pelo soberano e a precariedade que sua vida e seus bens adquirem enquanto considerados meros súditos. A vida humana, a liberdade e a propriedade, principalmente vislumbrados sob o ponto de vista econômico, começam a ser exigidos como garantias legais, precipuamente aquelas referentes aos contratos, com a garantia, mas não intromissão na autonomia privada (LOCKE, 2006, p. 173). 
grandes mazelas sociais, como o crescimento da taxa de natalidade, a formação de grandes aglomerados urbanos, marcados por assombrosas desigualdades entre as classes operária e empresarial, resultando na equiparação da mão-de-obra a uma mercadoria qualquer, na qual a venda barata da força laboral resultou de uma questão de sobrevivência.

Em função do exacerbado crescimento da população urbana, com a alta taxa de natalidade e aumento da mortalidade infantil, concentração de pessoas nas cidades e fábricas, há gênese de uma consciência política, fazendo os operários solidarizarem-se com os demais e organizarem-se em sindicatos e cooperativas para exigir do Estado soluções aos conflitos entre capital e trabalho que se instauravam (VIEIRA, 2004, p. 199).

O desemprego crescente, a formação de monopólios, a repercussão negativa no meio ambiente - poluição, congestionamento, esgotamento de recursos naturais -, o surgimento de teorias socialistas e o eclodir da Primeira Grande Guerra pressionavam o Estado a iniciar um gradativo processo de intervenção, com o escopo de atenuar os conflitos de interesses e adaptar-se à luz das profundas mudanças políticas, econômicas e sociais 5 .

O Estado Social preconizava uma intervenção maior do Poder Público no âmbito econômico, haja vista a incapacidade de a economia, por si só, auto-regular-se e conseguir desenvolver-se, ao mesmo tempo, de modo a garantir a justiça social.

Obviamente tais ideais foram gradativamente implementados, não acontecendo subitamente e nem em razão de uma única transformação. Foi, sim, fruto de uma série de conquistas sociais e, destarte, tem como pressuposto a preservação da livre concorrência das forças do mercado e a obrigação do Ente Público de ordenar e dirigir o processo econômico, mas sempre com atenção e respeito aos valores de justiça social, bem-estar e interesse públicos (GRAU, 1978, p. 18-20).

Precipuamente o Poder Público inclui certas normas no ordenamento jurídico, impondo um alargamento das atribuições do Estado, inserindo o intervencionismo e mitigando a figura do Estado Burguês de Direito (constitucionalismo).

Todavia, somente após as Guerras Mundiais, a intervenção no domínio econômico foi acentuada e concretizada, com o mister de o Ente Público direcionar e organizar as atividades produtivas, estruturando-se não só em razão do embate global que se instalara, mas, outrossim, das crises e depressões dele advindas.

\footnotetext{
${ }^{5}$ Colocam-se, pois, entre a segunda metade do século XIX e início do século XX, em razão dos reclamos sociais a uma política mais intervencionista do Estado, por conta das conseqüências devastadoras provocadas pelo capitalismo desenfreado, três movimentos embasados filosoficamente nas idéias do Estado Social: Comuna de Paris (1871); Revolução Mexicana (1910); e Revolução Russa (1917).
} 
Posteriormente a esses conflitos em nível global, o capitalismo precisava de uma certa estabilização social, também no sentido de possibilitar mais condições e capacidade de consumo e assim evitar maiores colapsos e riscos financeiros e econômicos (MARQUES NETO, 2002).

Em prol do interesse coletivo e da justiça social, para garantir e propiciar a liberdade de iniciativa e o livre mercado, o Estado interveio mediante normas sociais e econômicas, inseridas nas constituições como forma de regulamentar as atividades, não se permitindo a extrapolação dos limites prescritos em lei (FONSECA, 2004, p. 260-261).

Esse capitalismo assistencial estabelecido, renovado pela própria estatização de setores da Economia, legitima o Estado a resolver os conflitos de classe - divisão entre grupos sociais economicamente discrepantes - e a reprimir os não partidários ao sistema descrito na constituição, por intermédio do Direito positivo (GRAU, 2004, p. 24-26).

A nova tendência ${ }^{6}$ foi explicitada primeiramente na Constituição mexicana de 1917, posteriormente observada na Constituição de Weimar (1919). No Brasil, somente na Constituição de 1934, as idéias intervencionistas mostraram-se presentes, disciplinadas no Texto Legal como Ordem Econômica e Social, influenciada pelos Textos Constitucionais estrangeiros no sentido de conter em seu bojo esses princípios fundamentais e sociais.

\section{PÓS-POSITIVISMO OU NEOCONSTITUCIONALISMO: O NASCIMENTO DA NOVA HERMENÊUTICA}

Após o período nazi-fascista, reconstroem-se os direitos universais e, em âmbito internacional, surgem os pactos e tratados dispondo sobre os direitos fundamentais, proteção dos direitos humanos e modelos de Estado que contemplem as várias dimensões do ser humano e dos direitos materiais.

Os valores sociais de convivência humana, num contínuo processo de desenvolvimento e depuração, podem elevar a convivência social a um patamar de plena harmonia da sociedade. Visa-se à construção de um ambiente mais adequado, com o respeito e elevação do homem à convivência com dignidade humana.

\footnotetext{
${ }^{6}$ Também chamada de democracia liberal, institui uma política social embasada na igualdade entre os cidadãos, mitigando as desigualdades econômica e social e protegendo os indivíduos com serviços e atividades de natureza pública e geral, sempre revestidas por instrumentos legais a fim de restar prevalente o interesse público e as políticas sociais em detrimento das imposições do mercado capitalista (VIEIRA, 2004, p. 214-215).
} 
À luz dessas mudanças gradativamente implementadas na sociedade com o alvorecer dos ideais de Estado Social, verificou-se a necessidade de se analisar a Constituição como um receptáculo de normas prospectivas, possibilitando a construção de um futuro mais digno a todos aqueles sob a égide do Texto Constitucional. A possibilidade de compreensão desse contexto fica a cargo da hermenêutica jurídica constitucional, que também deve proporcionar ao Direito uma análise não isolada de valores éticos e políticos.

Nesse sentindo, tem-se o pós-positivismo como uma evolução da consciência humana na percepção dos valores, pois o homem almeja ir além daquilo que está simplesmente posto e previsto. Invoca-se novamente a idéia de prudência nessa nova maneira de se pensar o Direito.

Da mesma forma que o jusnaturalismo, enquanto gama de princípios não positivados, foi superado pelo positivismo jurídico de Kelsen - que aplaudia a forma e a validade lógico-formal da norma dentro do ordenamento jurídico, não considerando uma interpretação do Direito baseada em juízos de valor -, esta última corrente deu espaço ao pós-positivismo ou neo-constitucionalismo jurídico ${ }^{7}$.

Como representantes e defensores deste novo paradigma de pensamento tem-se Dworkin e Alexy, numa corrente ligada à recuperação da força normativa dos princípios de direito (valores); e Chaïm e Perelman, que procuram fundamentos para as decisões judiciais (CAMARGO, 2001, p. 141).

A questão constitucional pressupõe uma releitura das regras com relação aos princípios constitucionais, que ganham normatividade em razão de uma interpretação mais ampla.

O pós-positivismo é uma reformulação do positivismo jurídico, é a observância das convenções do passado em busca de uma adaptação das normas à luz da realidade constitucional, em que não mais vige o sistema fechado de regras e rigorismo lógico-formal, mas sim uma interpretação e aplicação das normas permeadas de valores e princípios, que, neste contexto, ganham normatividade.

O cerne do pós-positivismo é a teoria baseada em princípios. Para todo problema existe uma melhor solução - não uma resposta correta ou errada, mas sim a melhor resposta ao caso concreto. Assim, não há lacunas no Direito, pois essa racionalidade do magistrado, que age com prudência e no sentido de fornecer a decisão mais adaptada e concertada aos princípios e

\footnotetext{
${ }^{7}$ No que concerne à terminologia "pós-positivismo" ou "neo-constitucionalismo" diz-se que há certa imprecisão no termo pós-positivismo, no qual se deposita uma idéia de algo novo, compreensão errônea, haja vista a idéia de superação do positivismo por uma forma mais prudente, adequada e valorativa. O neo-constitucionalismo é entendido como um aprimoramento do termo, pois atrai à idéia do direito constitucional, enquanto a terminologia "positivista" abrange mais do que apenas este ramo do direito. Se se analisar que a Teoria Geral do Direito não é uma seara específica do direito, não se pode restringir o termo a uma área específica. Na pior das hipóteses, seria uma espécie do gênero "neo-positivismo".
} 
valores importantes no âmago social, impede a insolubilidade dos chamados hard cases (casos difíceis $)^{8}$.

O ordenamento jurídico apresenta incongruências. O juiz não tem poderes discricionários, uma vez que tal fato cingiria as decisões ao âmbito político em contraposição ao jurídico. Se as normas constitucionais fossem aplicadas conforme a política, a Constituição seria entendida como programática, raciocínio equivocado, conquanto o conteúdo deste termo, para alguns, é entendido como uma simples "possibilidade", ou seja, que as garantias e valores importantes da Constituição, mormente direitos sociais, não vinculariam o Estado, porque seriam realizados apenas "se possível".

Os direitos humanos, neste diapasão, baseiam-se na idéia de que todos os Estados devem respeitar os direitos dos indivíduos conforme o princípio da dignidade da pessoa humana, tanto internamente quanto no âmbito da comunidade internacional, e de protestar caso estes preceitos não sejam observados. A proteção não deve restringir-se à competência nacional interna, sendo uma obrigação zelar por sua manutenção mesmo na esfera mundial (PIOVESAN, 2003, p. 30-33).

Nesse cenário, construíram-se os métodos de interpretação baseados no conjunto normativo e principiológico em âmbito constitucional, com uma variedade de técnicas e instrumentos cujo objetivo é analisar e interpretar conforme os valores e os fins almejados na Constituição, porém, dentro de uma visão sistêmica, de um panorama global, denominada hermenêutica jurídica constitucional.

[...] dada a preponderância das normas constitucionais sobre as demais que integram o ordenamento jurídico, a hermenêutica constitucional elaborou uma série de princípios que devem servir de orientação ao intérprete, tanto para interpretar as normas constitucionais quanto as infraconstitucionais. São os princípios de hermenêutica constitucional, a serem observados, quando da utilização dos múltiplos métodos possível de serem utilizados por quem interpreta. (GOMES, 2002, p. 44)

\footnotetext{
${ }^{8}$ Dworkin, criticando o positivismo jurídico, propõe que, se se deseja tratar os princípios como direito, "faz-se mister rejeitar três dogmas dessa doutrina. O primeiro [...] é o da distinção entre o Direito de uma comunidade e os demais padrões sociais (social standards) aferidos por algum test na forma de regra suprema (master rule). $\mathrm{O}$ segundo referente [...] a 'discricionariedade do juiz'. E, finalmente, [...] uma lei - impõe tal obrigação, podendo ocorrer, todavia, a hipótese de que num caso complicado (hard case), em que tal lei não se possa achar, inexistiria a obrigação legal, até que o juiz formulasse nova regra para o futuro. E, se a aplicasse, isto configuraria legislação ex post facto, nunca o cumprimento de obrigação já existente" (DWORKIN apud BONAVIDES, 2003, p. 265).

${ }^{9}$ Assim, não se pode dar efetividade a todas essas normas em dado momento, mas sim um desenvolvimento, implementado com o passar do tempo, de tais valores por meio de políticas públicas, compreensão esta que contribui para não dar efetividade à Constituição. O termo "política" de Dworkin, então, deve ser compreendido como correspondente à norma que estabelece objetivos mediante a adequação de conduta com o fim almejado com tais desideratos.
} 
A maior revolução nessas formas interpretativas verifica-se na chamada Nova Hermenêutica, tendo como cerne as interpretações baseadas nos princípios que dão fundamento ao entendimento que se tem de Estado Democrático de Direito. A mudança, que também possibilitou buscar sentido tendo como base os princípios derivados do valor Democracia num Estado de Direito, consiste no respeito à dignidade da pessoa humana como valor mais relevante de uma sociedade.

\section{O ESTADO DEMOCRÁTICO DE DIREITO E O PRINCÍPIO DA DIGNIDADE DA PESSOA HUMANA}

O Estado Democrático de Direito - em que o Direito deve ser visto como instrumento de transformação social (STRECK, 2005, p. 33) - engloba princípios como o da constitucionalidade, democracia, justiça social, igualdade, divisão dos poderes, legalidade e segurança jurídica.

Mostra-se clara a todas as luzes a obrigação de o Estado obedecer e agir segundo os preceitos constitucionais não somente se sujeitando às normas ali depositadas, mas, outrossim, por intermédio de seus órgãos de direção política e administrativa, desenvolver "atividades econômicas conformadoras e transformadoras no domínio econômico, social e cultural, de modo a evoluir-se para uma sociedade democrática cada vez mais conforme aos objetivos da democracia social [...]" (STRECK, 2004, p.20).

\footnotetext{
o característico do Estado de Direito é precisamente a transmutação dos fenômenos de poder em Direito e, sobretudo, que a atividade política, uma vez cristalizada em forma jurídica, fica submetida ela mesmo ao Direito. Negam esta nota qualificativa todos os que, explícita ou implicitamente, sustentam a crença de que o poder prima sobre o Direito, e consideram, em conseqüência, que não cabe controle jurídico sobre a atividade política (LAVILLA apud STRECK, 2004, p. 24).
}

Esses princípios, decorrentes da Democracia e condizentes com o princípio da dignidade da pessoa humana, servem de balizas orientadoras para esse novo modelo de Estado, que inexiste no caso de tais valores restarem desrespeitados e/ou não forem levados a sério, haja vista se tratar de condições básicas que a sociedade deseja ver realizadas, enquanto meio de manter a harmonia e a paz social. Não há democracia sem o respeito aos direitos fundamentais e aos direitos humanos. 
O homem é um ser social e político, incapaz de sobreviver furtando-se de qualquer convívio com seus semelhantes. Mencionava Rousseau (1999, p. 54-55) ser a família a mais antiga das formas de sociedade política, sendo a única maneira natural - no sentido de se fazer necessária -, em decorrência desse próprio mister instintivo do ser humano.

Na história da Humanidade, segundo concepção contratualista, observa-se a evolução do homem quando os indivíduos saem do estado de natureza, onde a posse é precária, bem como a integridade física e a paz, para, mediante um pacto, um acordo entre determinado número de pessoas, possa existir a união para um convívio sob a égide de um Estado civil, dirigido por leis claras cujo objetivo era a garantia de auto-preservação e manutenção de bens ${ }^{10}$. O homem se deu conta da imprescindibilidade de regras de convivência fundamentadas no valor máximo de dignidade da pessoa humana, para manutenção da sobrevivência harmônica, justa e igualitária.

Tornam-se os princípios constitucionais mais palpáveis e eficazes, pois de simples peças dadas à integração do sistema em hipóteses de lacuna, passaram à base do ordenamento jurídico, servindo de normas de estrutura - destinadas ao legislador -, de princípios com grau de efetividade e coercitividade - a tal ponto de tornarem-se passíveis serem exigidos por meio de proteção jurisdicional como direitos subjetivos - e, finalmente, como valores fundamentais de ordem moral, destinados aos cidadãos para manutenção harmônica da convivência social.

\section{Importância e aplicação prática da nova hermenêutica}

Não é difícil imaginar a relevância de tais conceitos aos profissionais tanto da área jurídica como de quaisquer outras searas do conhecimento humano. Ao primeiro, a importância é diretamente ligada à feitura das normas jurídicas, porquanto o intérprete do Direito vai utilizar a melhor técnica oferecida pela hermenêutica para observar se o texto do Direito positivo é equivalente e condizente com o plano da realidade, onde se verifica a concretização das relações humanas. Deve haver consonância entre as condutas humanas prescritas nos comandos legais e o conteúdo principiológico exigido pela Constituição para seus respectivos fins.

O exegeta não só interpretará aquilo prescrito pelas normas. Cabe observar o mundo do ser, que está em constante modificação e adaptação, para fazer a melhor interpretação da norma ou do caso concreto. Daí a importância de, juntamente com as técnicas de hermenêutica, utilizar-se de várias áreas do conhecimento para dar significado a uma situação, seja ela do mundo do ser ou do mundo do dever ser.

\footnotetext{
10 "Por isso, o objetivo capital e principal da união dos homens em comunidades sociais e de sua submissão a governos é a preservação de sua propriedade. O estado de natureza é carente de muitas condições”. (LOCKE, 2006, p. 156)
} 
Nesse sentido, faz-se referência aos sujeitos da interpretação, indivíduos que devem construir e contribuir com o saber teórico mediante um processo educacional democrático, qual possibilite a apreensão de sólidos fundamentos políticos, éticos, culturais e jurídicos, com o intuito de criar uma visão ampla, profunda e multifacetada.

Mesmo aqueles que não trabalham diretamente com o Direito devem ter acesso à educação como forma de adquirir senso crítico e espírito de cidadania e solidariedade, afinal, o acesso à informação e à liberdade de expressão são formas de dar efetividade e concretude aos princípios que delineiam a plena vivência do Estado Democrático de Direito. (GOMES, 2002, p. 53-55)

[...] só a educação possibilita tal conscientização e o pleno desenvolvimento da pessoa. Só ela é capaz de libertar o indivíduo e os povos das amarras da ignorância a respeito de seus próprios direitos, valores e dignidade, bem como sobre os direitos, valores e dignidade do outro, de modo a ver neste um semelhante e não um inimigo. Só a educação forma o sujeito autônomo, pois somente ela é capaz de abrir-lhe os olhos para dimensões da realidade inacessíveis por outros meios (GOMES, 2005, p. 57).

A educação é a força motriz do desenvolvimento social, ético, político, cultural e moral, além de propiciar ao indivíduo a vivência de todos os direitos e deveres em sua plenitude, fazendo, ademais, a difusão do conhecimento e das técnicas de interpretação do Direito com o intuito de formar cidadãos conscientes de seu papel na sociedade, proporcionando a vivência da liberdade de informação e expressão em seu grau mais alto, como instrumento disseminador e modificador de idéias.

O desiderato maior do Estado Providência ou Intervencionista é que todos os indivíduos tomem ciência de sua importância como cidadãos e passem a agir e exigir o cumprimento dos princípios e das normas de condutas humanas realizadores dos valores básicos almejados pela sociedade.

Um exemplo duplamente relevante, pois trata da importância da Hermenêutica em áreas do conhecimento humano diferentes da jurídica e da aplicação pragmática dos princípios que cingem o Estado Democrático de Direito - tomando por base que dele decorre a necessidade de verificação dos demais princípios relevantes à manutenção desse modelo de bem-estar social é o da função e responsabilidade social das empresas no Brasil. 


\section{FUNÇÃO E RESPONSABILIDADE SOCIAL DAS EMPRESAS}

A Constituição Federal de 1988 dispõe em seu Título VII sobre a Ordem Econômica e Financeira, sendo que no primeiro capítulo, mais precisamente em seus Arts. 170, 173 e 174, traz alguns princípios e institutos que não apenas disciplinam, mas também prescrevem o modelo econômico que deve ser verificado nas relações e condutas humanas na seara econômica.

Conforme leciona Eros Roberto Grau, a idéia de "relações econômicas" ou "atividade econômica" serve de indicação, retratando não o mundo do ser, o modelo empírico de Economia, um modo de produção econômica. "Assim, ordem econômica, parcela da ordem jurídica (mundo do dever-ser), não é senão o conjunto de normas que institucionalizam uma determinada ordem econômica (mundo do ser)" (GRAU, 2004, p. 58-63).

As empresas privadas, ao realizarem atividades de mercado, devem nortear-se pelos princípios estipulados no Texto Constitucional, uma vez que eles possibilitam ao particular agir segundo as regras da livre concorrência e propriedade privada - necessárias ao desenvolvimento de acordo com o regime econômico capitalista -, porém, sempre observando os princípios que foram inseridos na Constituição para possibilitar a efetivação de alguns valores provenientes do modelo de Estado Social, quais sejam: defesa do consumidor, defesa do meio ambiente, respeito à função social da propriedade, redução das desigualdades regionais, busca do pleno emprego e favorecimento de empresas de pequeno porte.

Aqueles estabelecimentos empresariais limitados a agir única e exclusivamente segundo o constante nos ditames da Constituição, nada mais fazem do que cumprir com seu dever legal. Realizam assim a sua função social.

Há, no entanto, um crescente número de empresas que optam por fazer além da sua obrigação constitucional, entendendo possuir um papel maior no cenário social - seja em busca de benefícios por parte do Poder Público, seja em razão do marketing social que a atitude propicia - e, nesse sentido, investindo em áreas e serviços de interesse público.

O investimento empresarial em serviços que, em última análise, seriam de incumbência do Estado, ocorre tanto diretamente, com a empresa criando fundações ou organizações sem fins lucrativos - Terceiro Setor empresarial - com o intuito de realizar esses escopos, quanto indiretamente, com a ajuda de custo, fornecimento de capital, estrutura logística e pessoal como, por exemplo, no incentivo de empregados a trabalhar como voluntários - em organizações não-governamentais e sem fins lucrativos (ONGs). 
Obviamente o setor empresarial age em consonância com a racionalidade econômica, prática e finalística. A racionalidade teleológica - meio-fim; custo-benefício - funciona como um paradigma para a racionalidade econômica, observada no ethos das relações mercantis. As empresas privadas, embora com desiderato diverso dos fins sociais, não deixam de estar inseridas num contexto social, impedindo certos comportamentos contrários aos princípios e valores éticos que são característicos deste meio.

Não obstante os negócios sejam regidos pelas próprias regras de mercado, cuja missão é obter o máximo de benefício (lucro) possível, devem legitimar sua existência e atuação por intermédio da confiança do consumidor, fazendo-o preferir sua empresa e seus produtos ao invés de outra que não demonstre os mesmos compromissos assumidos com o público.

O ethos da empresa não é guiado por uma consciência moral - porquanto isso não lhe possibilitaria alcançar seu fim (lucro) - mas por uma ética empresarial que prime pela responsabilidade social, norteadora de suas decisões e ações e principalmente motivada pelo marketing, atrativo que o compromisso moral - traduzido em confiança - com a sociedade proporciona. (CORTINA, 2001, p. 263-277)

Porém, isso não significa que não esteja cumprindo seu papel no âmbito social, mesmo se o objetivo maior a ser alcançado restrinja-se ao recebimento de benefícios governamentais.

É certo que tais atribuições estatais como assistência social, educação e proteção do meio ambiente são obrigações do Poder Público, políticas de Estado prescritas no Texto Constitucional que devem ser executadas. A partir do momento em que foi promulgada a Constituição Federal de 1988, com todos os princípios de dignidade da pessoa humana, do qual decorrem os valores básicos de sobrevivência e vida digna, é encargo do Estado prover todos esses serviços de maneira satisfatória à população.

Todavia, embora no Brasil haja uma enorme carga tributária criada com o fim de custear este tamanho de Estado que a sociedade brasileira resolveu ter, as despesas são maiores e a receita insuficiente para oferecer esses serviços, com qualidade, à sociedade em sua totalidade.

O corpo social, por sua vez, verificando a ineficiência estatal e a alta lucratividade das grandes empresas, começou a cobrar uma atuação maior das empresas na seara de serviços públicos destinados à sociedade.

Essa mudança de racionalidade estratégica para a racionalidade comunicativa defendida por Habermas (FABIÃO, 2000, p. 68) ocorreu em função da transformação do indivíduo num ser humano mais reflexivo, mais consciente de seu papel e do papel dos demais membros da sociedade. É o chamado "consumidor-cidadão", que não pensa somente segundo a lógica 
racional-liberal, na qual só importava o produto final - e mais em conta. Percebe-se o afloramento de uma visão global, com uma maior consciência dos problemas ecológicos do planeta, bem como as graves mazelas sociais e econômicas.

Daí a idéia do benefício às empresas que agem de maneira ética e responsável, pois além de receberem - em alguns casos - incentivos de ordem fiscal em razão dos serviços públicos prestados, ainda lucram com a propaganda positiva no âmbito social, sendo preferidas pelos consumidores-cidadãos.

As empresas são obrigadas a dialogar com a sociedade, agir como "estrategistas sociais" para tentar ver os resultados econômicos e financeiros dos investimentos sociais realizados por elas. Há muitas nuances nessa matéria envolvendo função e responsabilidade social, mas o importante na verificação desses dois institutos é observar como todas as áreas do conhecimento humano necessitam da interpretação, do diálogo e da liberdade de agir e buscar seu papel dentro da sociedade.

Comenta o professor Fabião (2000, p. 73) que "o desafio das empresas que querem ser reconhecidas como socialmente responsáveis é desenvolver mecanismos de interação democrática com seus parceiros estratégicos, tais como as comunidades locais”.

A Democracia envolve diálogo. Os cidadãos cobram mais das empresas e estas respondem aos anseios sociais. O Estado, por sua vez, observando que não pode cumprir com todas as funções que lhe foram atribuídas, incentiva cada vez mais os investidores empresariais a agirem no terceiro setor, realizando serviços alheios à sua competência.

\section{RESPONSABILIDADE SOCIAL E O ESTADO DEMOCRÁTICO DE DIREITO}

Além de a responsabilidade social das empresas ser um assunto assaz discutido em decorrência das dúvidas que este novel instituto gera no campo do Direito, ainda sua análise se faz necessária pelos benefícios, por parte do Poder Público, que muitas empresas recebem sob a alcunha de socialmente responsáveis.

Existe o interesse em conceder incentivos fiscais àquelas empresas que cooperam com o Poder Público no agir com responsabilidade social. É uma justificativa bastante razoável ajudar os particulares quando eles fazem a mais do que sua obrigação legal, em termos sociais, haja vista uma certa desoneração do Estado com serviços públicos.

A partir do momento em que a Administração Pública torna-se falha, ineficiente e insuficiente a ponto de tornar mister a criação de institutos jurídicos híbridos - em decorrência 
da quebra do modelo baseado na dicotomia do Direito Público/Privado (MARQUES NETO, 2002) - para suprir as necessidades públicas, deve encontrar mecanismos para garantir a manutenção e ajuda privada nos assuntos de interesse público.

Quando se fala em Estado Democrático de Direito, a concepção de Habermas nos remete a um modelo de Estado que tem como pressuposto básico alguns direitos sociais, políticos, culturais e econômicos plenamente positivados, para proporcionar uma situação de perfeita possibilidade de estabelecimento do diálogo entre os concernidos em dada questão que afeta a sociedade, para que então se possa verificar, na prática, o que se entende por democracia.

E esse diálogo é imprescindível não apenas no campo da política - aqui entendida como uma forma de se estabelecer uma maior participação do indivíduo na feitura de normas jurídicas que vão vincular a todos de uma dada sociedade - mas também em situações cotidianas como numa relação entre empresa e sociedade. Com a globalização e o neoliberalismo, pode-se dizer que os Estados perderam, em muito, sua capacidade decisória, de realizar e implementar políticas públicas em diversas áreas de interesse social. Esse vácuo teve que ser suprido pelas empresas.

Mas como atuantes na área social, não podem mais as empresas agirem conforme seu talante, seguindo uma racionalidade de produção e consumo que leva ao desenvolvimento de sua atividade em completa desconsideração ao ethos que as circunda. Os próprios princípios decorrentes da dignidade da pessoa humana e outros valores necessários á plena realização do processo dialógico democrático, fazem com que a empresa estabeleça essa comunicação com a sociedade, ouvindo seus reclamos e atuando, de maneira responsável, naqueles setores que estão carentes de serviços e bens.

Não basta às empresas agirem unicamente segundo uma função social que nada mais demonstra que elas cumprem à risca o prescrito no ordenamento jurídico. Consoante o verificado, essa atuação nada mais acrescenta, nada mais significa do que a realização do que obrigatoriamente é imposto a qualquer cidadão ou instituição sob a égide do sistema jurídico pátrio.

A responsabilidade social empresarial decorre da implementação de atividades que vão além do dever legal, mas que estão em conformidade aos princípios que balizam o Estado Democrático de Direito, que, em última análise, é um modelo de Estado que prima pela consecução do desenvolvimento econômico. E as empresas receberam, em razão dos reclamos sociais, a missão de auxiliar o Poder Público a alcançar o almejado desenvolvimento.

Assim, a atuação empresarial deverá ser acordada aos valores que a sociedade deseja ver realizados. Mesmo agindo de acordo com a racionalidade econômica que a atividade em- 
presarial exige para sua manutenção, ainda será um agir empresarial que terá o escopo de criar um vínculo de confiança e credibilidade com a dinâmica social.

A interpretação do Direito segundo a Nova Hermenêutica possibilita que os valores que dão o substrato ao Estado Democrático de Direito sejam, em certa parte, vivenciados pelas empresas, que buscam adquirir a confiança da comunidade na qual estão inseridas. Desta forma, não apenas o Estado estará autorizado e legitimado a conceder algum tipo de benefício à empresa, como também a própria sociedade, que de certa forma cria um vínculo de segurança mútua entre si e atividade da empresa.

\section{CONCLUSÃO}

A sociedade e as relações humanas estão em constante modificação, e o Direito tenta acompanhá-las e daí a necessidade de técnicas de interpretação que acompanhem esta dinâmica, com maneiras acessíveis e democráticas que propiciem esse livre diálogo entre as pessoas, como verificado no caso acima exemplificado.

O direito deve ser conectado ao seu humano e, por esse motivo, sempre estudado em suas múltiplas perspectivas.

Resta ao ser humano agir como um verdadeiro cidadão, isto é, exercendo seus direitos, cumprindo seus deveres, atuando como fiscal da lei e do Governo, enfim, atuante no âmago social, exigindo do Estado o cumprimento de todas as atribuições e objetivos previstos, desde logo, no Preâmbulo Constitucional, trazendo nada mais do que os valores básicos a serem realizados visando à harmonia e paz social e dignidade humana, cobrando a mesma postura das atividades empresariais que auxiliam o Poder Público no afã de conseguir o desenvolvimento, que nada mais é do que a plena vivência de um Estado Democrático de Direito.

\section{REFERÊNCIAS}

BONAVIDES, Paulo. Curso de Direito Constitucional. São Paulo: Malheiros, 2003. . Do Estado Liberal ao Estado Social. São Paulo: Malheiros, 2004.

. Teoria Constitucional da Democracia Participativa: Por um Direito Constitucional de luta e resistência. Por uma Nova Hermenêutica. Por uma repolitização da legitimidade. São Paulo: Malheiros, 2001. 
CAMARGO, Margarida Maria Lacombe. Hermenêutica e Argumentação: uma Contribuição ao Estudo do Direito. Rio de Janeiro: Renovar, 2001 (capítulo 3 - p. 139-192).

CARRAZZA, Roque Antonio. Curso de Direito Constitucional Tributário. São Paulo: Malheiros, 2005.

CORTINA, Adela. Ética Aplicada y Democracia Radical. Madrid: Tecnos, 2001. $\mathrm{F}$

ABIÃO, Maurício França. O negócio da ética: um estudo sobre o terceiro setor empresarial. Universidade do Estado do Rio de Janeiro. 2000.

FIGUEIREDO, Lúcia Valle. Curso de direito administrativo. São Paulo: Malheiros, 2004.

FILHO, Alberto Venâncio. A Intervenção do Estado no Domínio Econômico: Direito Público Econômico no Brasil. Ed. fac-similar. Rio de Janeiro: Renovar, 1998.

GOMES, Sergio Alves. Hermenêutica Jurídica e Constituição no Estado de Direito Democrático. Rio de Janeiro: Forense, 2002.

$\mathrm{z}$

. O princípio constitucional da dignidade da pessoa humana e o direito fundamental à educação. Revista do Direito Constitucional e Internacional, ano 13, abr./jun. 2005. São Paulo: Revista dos Tribunais, 2005.

GRAU, Eros Roberto. A Ordem Econômica na Constituição de 1988 (interpretação e crítica). São Paulo: Malheiros, 2004.

LOCKE, John. Segundo tratado sobre o governo civil e outros escritos: ensaio sobre a origem, os limites e os fins verdadeiros do governo civil. Trad. Magda Lopes e Marisa Lobo da Costa. Bragança Paulista: Editora Universitária São Francisco; Petrópolis: Vozes, 2006

MARQUES NETO. Floriano Peixoto de Azevedo. Regulação Estatal e Interesses Públicos. São Paulo: Malheiros, 2002.

PIOVESAN, Flávia. Temas de Direitos Humanos. São Paulo: Max Limonad, 2003.

ROUSSEAU, Jean-Jacques. Do Contrato Social. Trad. Lourdes Santos Machado. São Paulo: Nova Cultura, 1999.

SCAFF, Fernando Facury. Responsabilidade Civil do Estado Intervencionista. Rio de Janeiro: Renovar, 2001.

SILVA MARTINS, Ives Gandra da (coord). Curso de Direito Tributário. São Paulo: Saraiva, 2001.

STRECK, Lênio Luiz. Hermenêutica Jurídica e(em) Crise: Uma exploração hermenêutica da Constituição do Direito. Porto Alegre: Livraria do Advogado, 2005. 
. Jurisdição Constitucional e Hermenêutica: Uma nova crítica do Direito. 2. Rio de Janeiro: Forense, 2004.

VIEIRA, Evaldo. Direitos e Política Social. São Paulo: Cortez, 2004. 